\title{
A home for the modern nomad: Extended stay hotels
}

Received (in revised form): 8 May 2008

\section{Elke Geieregger}

is an associate with HVS's London office. Having worked as a junior consultant and in various roles in hospitality accounting with Hilton and Morgans Hotel Group, she is now completing assignments in numerous European countries. Originally from Austria, Elke holds a BA (Hons) in tourism management from IMC Krems, Austria, and the Plekhanov Economic University, Moscow and is a part-qualified member of the Chartered Institute of Management Accountants (CIMA).

\section{Arlett Oehmichen}

is a senior associate with HVS's London office, specialists in hotel valuation and consultancy. She joined HVS in mid-2006 after six months' experience in the hotel investment industry, as well as operational hotel experience during university placements with Hilton and $\mathrm{NH}$ Hoteles. Arlett has studied Business Administration at the Dresden University of Technology, Germany and Universidad de Cordoba, Spain. Since joining HVS, she has conducted numerous valuations and feasibility studies in Europe and Africa. Arlett has worked on assignments for hotels as well as mixed-use developments comprising residential, rental pools, golf courses and marinas.

\begin{abstract}
As extended stay hotels gain in popularity across Europe $-\mathrm{a}$ few pioneer properties are nearing completion or are already in operation - guests, developers and operators are excited about the prospects for this new class of hotel. HVS analyses the supply and demand patterns that govern the serviced apartment sector in Europe and ultimately answers the question: extended stay - where are the opportunities?
\end{abstract}

\section{Keywords:}

extended stay, aparthotel, serviced apartments, hotel brands, operating characteristics, US-Europe comparison extended stay

Journal of Retail and Leisure Property (2008) 7, 216-233.

doi:10.1057/rlp.2008.16; published online 18 June 2008

Elke Geieregger HVS - London Office 7-10 Chandos Street Cavendish Square London $\mathrm{W}_{1} \mathrm{G} 9 \mathrm{DQ}$, UK Tel: $+44(20) 78787700$ Fax: +44 (20) 78787799 E-mail: egeieregger@hvs.com Web: www.hvs.com

\section{INTRODUCTION}

In the past few years, the extended stay concept has continued its rapid growth in the USA; it is now a well-established model. Of equal appeal to developers, owners and operators, the extended stay product is still in high demand when it comes to the number of planned projects in the USA.

The introduction in Europe of some popular US extended stay brands seems, therefore, to be a natural development. HVS's London office has been involved in the introduction and development of serviced apartment operations for several years in many European markets and the UK in particular. Under the headings that follow, this paper highlights the opportunities for and the challenges facing the extended stay product. 
Table I: Indicative unit sizes for extended stay hotels $\left(\mathrm{m}^{2}\right)$

\begin{tabular}{llll}
\hline & Mid-market & Upscale & Deluxe \\
\hline Studio & 30 & 35 & 35 \\
One bedroom & 40 & 50 & 55 \\
Two bedrooms & 60 & 70 & 85
\end{tabular}

Source: HVS research

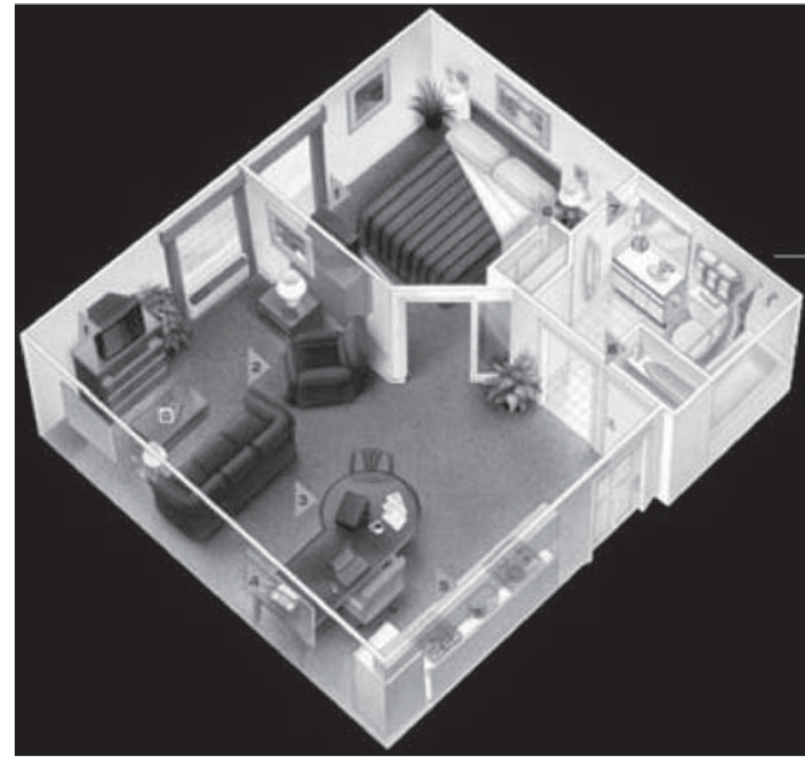

Figure I: Typical layout of an extended stay room

- Product Characteristics;

- Demand Profiles;

- The Players;

- Case Study: Selected UK Markets;

- Developing and Operating Extended Stay Hotels;

- Outlook;

- Conclusion.

\section{PRODUCT CHARACTERISTICS}

Although a classic hotel operator and a serviced apartment hotel share the same objective — selling a hotel room for a night — aparthotels and serviced apartment providers attempt to provide 'a home away from home', personalised service and larger living spaces.

Extended stay properties are specifically aimed at guests seeking to stay for an extended period of time in hotel-like accommodation. In meeting guests' needs, apartments tend to be larger than standard hotel rooms and include kitchen facilities (Figure 1). In Europe, the extended stay product includes primarily serviced apartments and aparthotels, with the former typically used to define commercially oriented properties 
All-suite (long-stay) hotel: Urban product offering a high standard of accommodation in configurations of one, two or three bedrooms and a standard of service that is comparable to a hotel product. An example is Staybridge Suites.

Serviced apartment: Usually defines an urban product. The standard of accommodation can range from budget to deluxe. In general, the level of service provided tends to be more limited than it is in an all-suite hotel. An example is Ascott.

Aparthotel: Usually refers to a resort product although may be used to define an urban product (eg, Citadines aparthotels). The standard of accommodation and services can vary from budget to deluxe.

in urban locations, and the latter used to define leisure-oriented properties in resort locations (although the distinction between the two is blurring). In this paper, we focus on the urban extended stay market.

\section{Size and capacity}

The size of extended stay properties can vary widely: from fewer than ten keys to more than 200 keys per property. From our experience in this sector, we estimate that the average size of extended stay properties in European cities would typically range from 100 to 120 keys. In particularly strong markets such as London, the average size of a property is likely to be some 150 keys.

The location of a property in either an urban area or a resort will define the target market of that property to a large extent and, as such, may influence the configuration and mix of studios, one-bedroom and twobedroom apartments. Guests staying for shorter periods are more likely to occupy studios, whereas longer-staying guests and families are more likely to occupy (larger) one-bedroom or two-bedroom apartments.

Based on our discussions with serviced apartment operators and our professional experience, Table 1 shows indicative unit sizes for various classes of extended stay hotel.

\section{Style and standard}

Serviced apartments and aparthotels can vary in style from modern to traditional and can range in standard from basic/moderate to upscale and deluxe. There is no official classification system for extended stay accommodation and standards and terminology can vary greatly across properties, creating much confusion about the product. Some extended stay properties use the international hotel star rating system to indicate the level and quality of the amenities provided. We provide an outline of the main terminology, as we understand it, that is used to describe the various standards of extended stay accommodation (Table 2).

\section{Quality of fit-out and amenities}

Most extended stay properties are fully furnished and contain en suite bathroom facilities, a fitted kitchen or kitchenette and a lounge/dining area that includes a sofa bed. The standard of a property is likely to define the level of amenities provided. Commercially oriented serviced apartments generally provide a working area, a desk and an office chair. Internet access and direct telephone/fax lines are important. 


\section{Public areas and services}

Public areas are usually limited to a small reception/lobby and, potentially, one small communal lounge/breakfast area. Serviced apartments in urban locations may provide a small meeting room or meeting rooms. The services provided include apartment cleaning (commonly once or twice per week, with optional daily service at extra cost), laundry and reception. Upscale properties may provide laundry equipment in each apartment, whereas properties of a lower standard may provide access to shared laundry facilities.

\section{Food and beverage facilities}

Extended stay properties may provide a breakfast room, but there is usually no restaurant or bar. If a restaurant/bar is provided, it is often leased out or operated by a third party. In many instances, extended stay properties recommend a range of partner restaurants nearby.

\section{Site prerequisites}

Typical criteria considered in an evaluation of potential extended stay development sites include the following:

- Proximity to commercial demand generators (corporate offices, business parks and so forth);

- Proximity to airports (ones with scheduled flights);

- Access to public transport;

- Proximity to restaurants, cafés, shops and nightlife;

- For those relocating, proximity to international schools;

- Road access and parking facilities.

\section{DEMAND PROFILES}

Generally, hotel demand and, as such, demand for serviced apartments, is divided into business and leisure and can be further subdivided by length of stay: one week, seven to 31 days, and more than 31 days. Typical serviced apartments in urban locations would generally generate the majority of their room nights in the medium-stay segment (60 per cent). Short stay (less than a week) might account for up to 30 per cent and long stay (31 days or more) for the remainder. We go on to consider the medium stay and long stay segments for both business and leisure travellers.

\section{Business demand}

Today's mobile workforce and flexible work arrangements form the basis of extended stay demand. Project managers, management consultants and senior management are often temporarily assigned to a foreign base or a different branch for a medium-term to long-term project. Professionals working on court cases or insurance cases might also require accommodation away from home for a few weeks. In some instances, general short-stay business travel can turn into extended stay demand, as serviced apartments offer more living, work and meeting space and, 


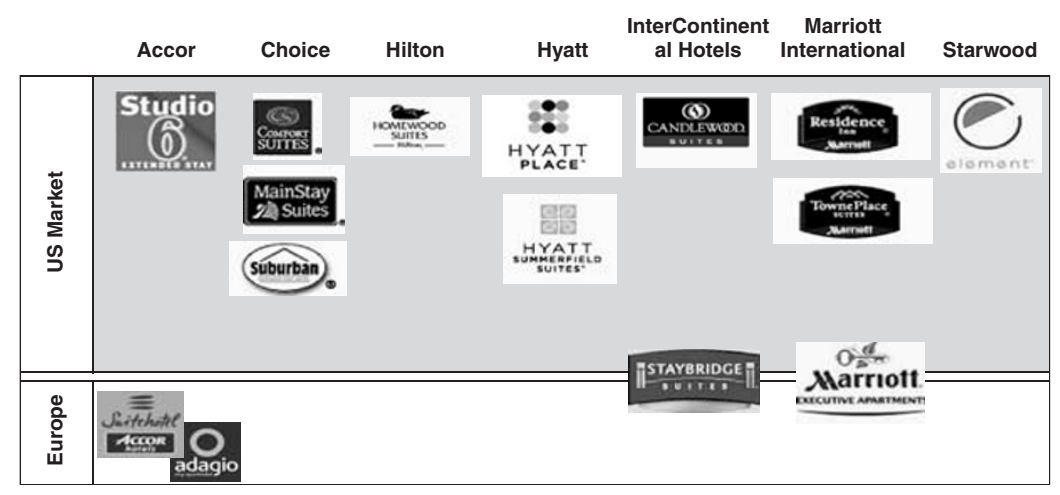

Figure 2: Major hotel brands and their extended stay brands Source: HVS research.

Table 3: Major extended stay brands in Europe

\begin{tabular}{|c|c|c|c|}
\hline Brands & Properties & Units & Locations \\
\hline \multicolumn{4}{|l|}{ Accor } \\
\hline Suitehotel & 20 & 2,566 & $\begin{array}{l}\text { Germany, Austria, Switzerland }-6 \text { hotels } \\
\text { France }-14 \text { hotels }\end{array}$ \\
\hline Adagio* & 16 & 2,300 & France and Italy \\
\hline \multicolumn{4}{|l|}{ Ascott group } \\
\hline Ascott & 45 & 4,944 & France $-3,522$ units \\
\hline Somerset & & & UK -85 I units \\
\hline \multirow[t]{2}{*}{ Citadines } & & & Belgium -322 units, Spain -131 units \\
\hline & & & Germany - 118 units \\
\hline \multicolumn{4}{|l|}{ Clarendon serviced Apts } \\
\hline Clarendon serviced Apts & 14 & 200 & London \\
\hline \multicolumn{4}{|l|}{ Fraser hospitality } \\
\hline Fraser suites & 8 & 633 & London, Paris \\
\hline \multicolumn{4}{|l|}{ Fraser place } \\
\hline \multicolumn{4}{|l|}{ Fraser residences } \\
\hline \multicolumn{4}{|l|}{ Marriott } \\
\hline Executive apartments & 4 & 265 & London, Budapest, Prague, Brussels \\
\hline \multicolumn{4}{|l|}{ Orco group } \\
\hline MaMaison & 4 & 144 & Bratislava, Prague,Warsaw, Budapest \\
\hline \multicolumn{4}{|l|}{ Prem group } \\
\hline Premier apartments & 12 & 600 & UK, Dublin, Antwerp \\
\hline \multicolumn{4}{|l|}{ Premier suites } \\
\hline \multicolumn{4}{|l|}{ Toga hospitality } \\
\hline Adina apartments & 3 & 350 & Copenhagen, Budapest, Berlin \\
\hline
\end{tabular}

*In a joint venture with Pierre \& Vacances

Source: HVS research

sometimes, better value than a hotel in a similar category. People attending exhibitions or training sessions, and the people providing those training courses, might also require longer-term accommodation. Performing artists, medical professionals, musicians and sports teams are also classic examples of a mobile workforce. Furthermore, business demand can also include people relocating and using temporary 


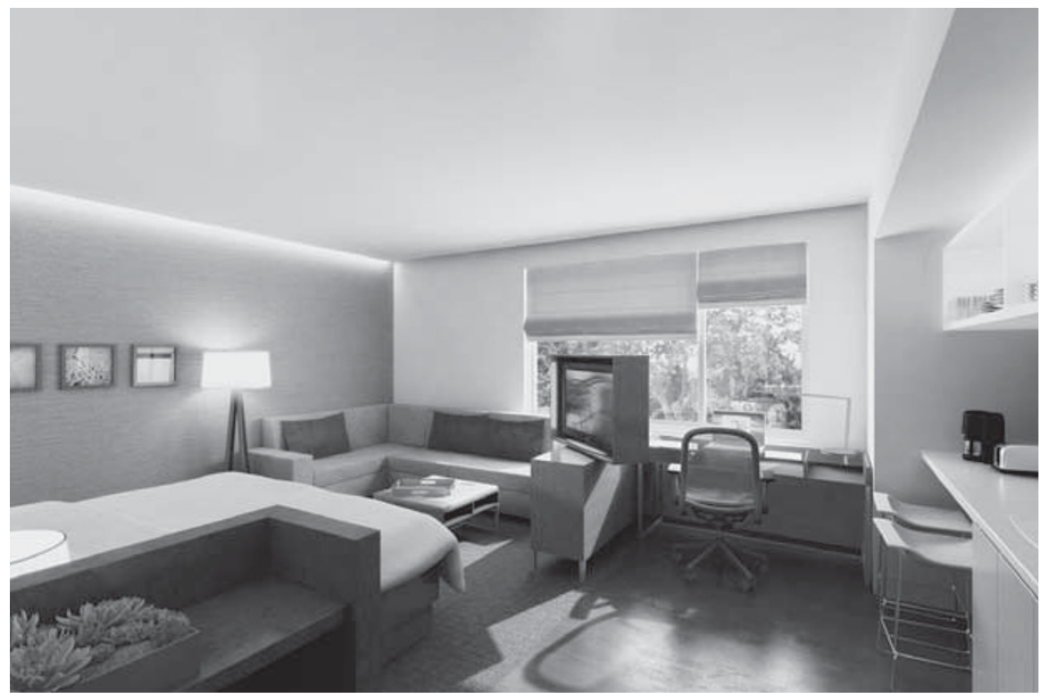

Figure 3: Element — bedroom view Source: Starwood.

Table 4: Selected future supply

\begin{tabular}{llll}
\hline Opening & Brand & City & Country \\
\hline 2008 & Citadines & Tbilisi & Georgia \\
& Adagio & Montrouge & France \\
& Adagio & Annecy & France \\
& Staybridge Suites & Liverpool & UK \\
Suitehotel & Marseilles & France \\
& Suitehotel & Nice & France \\
& Suitehotel & Reims & France \\
& Suitehotel & Prague & Czech Republic \\
& Ascott & Astana & Kazakhstan \\
& Citadines & Aktau & Kazakhstan \\
& Citadines & Edinburgh & UK \\
& Adagio & Brussels & Belgium \\
& Adagio & Basle & Switzerland \\
& Adagio & Vienna & Austria \\
& Adagio & Strasbourg & France \\
& Adagio & Nantes & France \\
& Suitehotel & Perpignan & France \\
& Adina & Frankfurt & Germany \\
& Adina & Berlin & Germany \\
& Adina & Hamburg & Germany \\
& Fraser Suites & Liverpool & UK \\
& Citadines & Munich & Germany \\
Staybridge Suites & Newcastle & UK \\
& Somerset & Moscow & \\
& Adina & Berlin & Russia \\
& Adina & Hamburg & Germany \\
& & & Germany \\
& & & \\
& & & \\
& & & \\
& & &
\end{tabular}

Source: HVS research

accommodation as an interim solution until private long-term accommodation can be found.

As with business demand in general, extended stay corporate demand is highly dependent on the global economy and, in particular, national economies. 


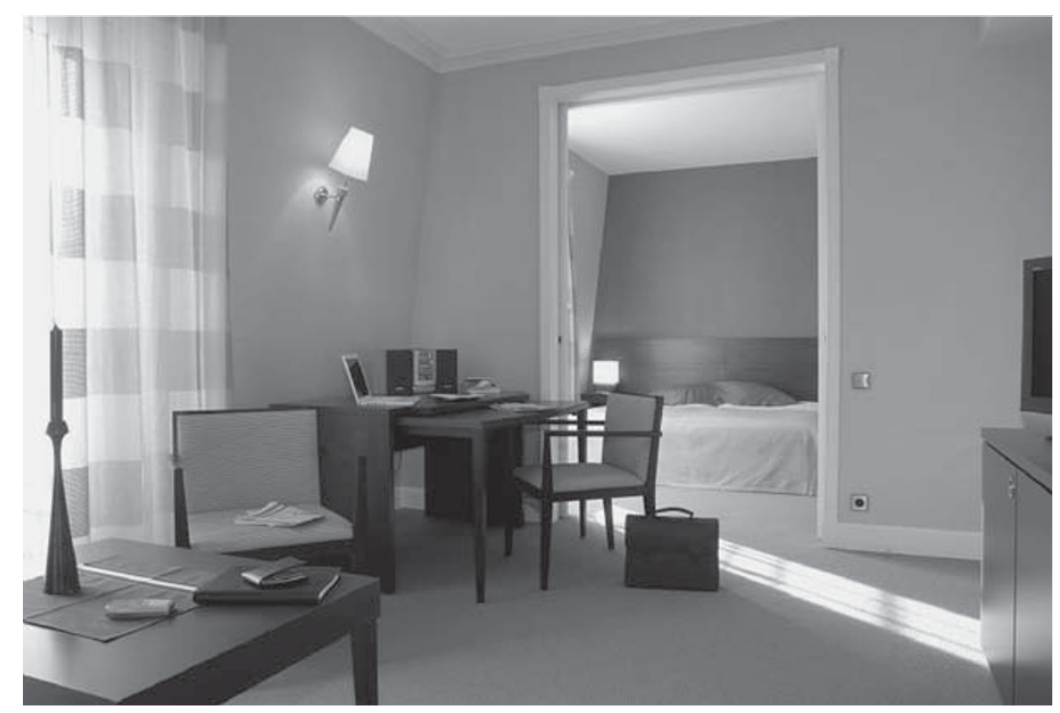

Figure 4: Adagio — living area Source:Adagio.

\section{Leisure demand}

Serviced apartments can provide large living spaces for people taking extended breaks or making shopping trips; shopping trips are a particularly popular pursuit among middle eastern visitors in major capitals such as Paris and London. Leisure demand comprises private individuals and families spending their holidays away from home. Families appreciate serviced apartments' good value for money, increased space and the opportunity to 'eat in' with their children. This demand is concentrated on the summer holiday season, when most families travel. We estimate that US visitors choose serviced apartments more frequently, as the serviced apartment market is fully established in the USA and Canada. Students, visiting friends and relatives, or hospital in-patients are a typical target market for the serviced apartment sector.

\section{THE PLAYERS}

\section{Current players in the USA}

The infrequent US traveller might not be aware of the multitude of extended stay sub-brands across the Atlantic. The seven largest global hotel corporations in some instances operate as many brands in the serviced apartment sector as they do in the classic hotel sector (Figure 2). As extended stay becomes more widely known in Europe, a number of these operators have detailed plans to move into, or are already in the process of moving into, the European market.

Established in 1962, Accor's Studio 6 brand currently flags 910 hotels (92,000 rooms) in the USA and Canada, whereas Choice pursues a multibrand strategy with its Comfort Suites, MainStay Suites and Suburban brands. More than 220 Homewood Suites properties, totalling more than 20,000 suites, are operated by Hilton in the USA. Summerfield 


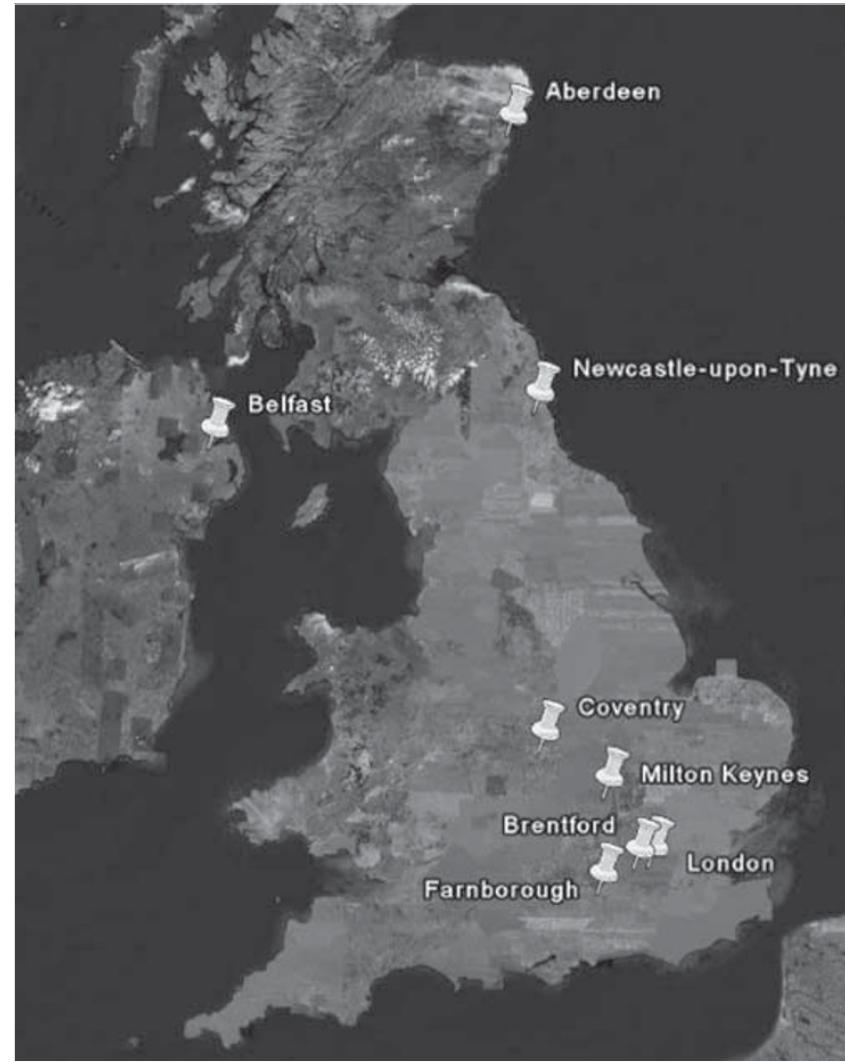

Figure 5: Extended stay locations in the UK

Suites was originally operated by Wyndham and was acquired by Hyatt in 2006. By March 2008, 30 Summerfield Suites will be in operation. Hyatt expects to be operating 120 Hyatt Place properties across the USA by then. InterContinental Hotels Group (IHG) is the first operator to bring its US brand to the UK; it will open its first Staybridge Suites, in Liverpool, in mid-2008. Candlewood Suites is present only in the USA at the moment. Starwood recently announced the launch of its Element brand (Figure 3); the first hotel is scheduled to open in Lexington,

Massachusetts, in early 2008. Marriott International's Executive Apartments are an extended stay pioneer, with a handful of successful properties in European capitals. In many instances, the apartment building is adjacent to a Marriott-operated hotel; this brings cost efficiencies and reservation referrals. Marriott operates two other extended stay brands in the USA (Residence Inn and TownePlace Suites).

\section{Current players in Europe}

Although the serviced apartment sector in Europe is relatively small compared to the US market, it is growing at an ever-faster pace (Table 3). In addition to global players such as Marriott Executive Apartments and Singapore-based Ascott Group, some local players such as Adina Apartments and MaMaison Residences have emerged. Adina has set up its first hotels in Copenhagen, Berlin and Budapest, and is now actively 
expanding in the German market, with five further projects under construction. MaMaison, owned by the Orco Group, has a portfolio of full service hotels and extended stay residences in central and eastern Europe. Accor has developed dedicated extended stay products in Europe; it is expanding strongly in Europe with the Suitehotel brand and the Pierre \& Vacances joint venture Adagio (Figure 4). Both brands have been adapted to suit the European market. Accor operates a large network of Studio 6 units in the USA and Canada. The Ascott Group operates three distinct brands to capitalise on different target markets: the exclusive Ascott, the upscale Somerset and the mid-market, familyoriented Citadines.

In terms of historic demand growth, the UK and Germany seem to be the strategic points of entry for the extended stay product. Our research into planned supply in Europe shows extended stay's preference for Germany. The Accor brands Adagio and Suitehotel are focused on the French market in the medium term.

Table 4 shows that future serviced apartment supply is not exhaustive and includes only those projects that have been confirmed by their respective operators.

\title{
CASE STUDY: SELECTED UK MARKETS
}

Over the last few years, HVS has been commissioned to analyse the extended stay market in numerous cities in the UK. This section gives a short summary of each market's characteristics and summarises that market's current suitability for extended stay operations (Figure 5).

\begin{abstract}
Aberdeen
Aberdeen's overall market mix reflects the area as primarily a short-stay destination, as would be expected from any destination that derives its demand primarily from business travel. We, however, note that the current market mix does not accurately reflect the requirements of the market. In other words, as only a small number of proper serviced apartment hotels are currently available in Aberdeen, much of the extended stay demand remains unaccommodated, and travellers settle for shorter, more frequent trips. For example, such travellers might come repeatedly to Aberdeen from Monday to Thursday for several weeks in a row. Extended stay business demand in the market area is derived mainly from the oil and gas companies in Aberdeen, the backbone of the city's economy. A reoccurring pattern in business demand is the rig workers who spend a few nights in hotels before being flown offshore from Aberdeen's heliport. Leisure demand in the market area is derived from travellers visiting relatives and friends, and from tourists to Royal Deeside and a number of sights in Aberdeen. Medium-stay business demand in the market area is derived mainly from the local oil and gas industry, and the research institutions in the city. These industries give rise to projectoriented work of a couple of weeks and require staff to attend specialised training courses. Aberdeen, for instance, has a training-drilling tower, located near the AECC.
\end{abstract}


In summary, Aberdeen is a very suitable market for extended stay hotels. A lack of professional operators, however, results in Aberdeen's potential not being fully realised at the moment.

\section{Belfast}

The economic environment in Belfast has seen steady growth over the past few years and, owing to favourable employment conditions, the city has been able to attract several large international companies.

Commercial demand, and meeting and conference demand for hotels in the market area are derived mainly from local businesses in the Belfast area, or from visitors attending exhibitions, conferences, trade fairs and exhibitions in the city.

From primary research conducted with local companies, we understand that corporate demand for extended stay properties is relatively low, as those international corporations with a branch in Belfast are usually also located either in London or in another European city. Therefore, company delegates coming to Belfast often trade longer stays for more frequent visits.

Guests staying at an extended stay product would, however, primarily be corporate guests on weekdays and extended stay products would find themselves competing with normal hotels for business. Belfast does not offer any extended stay product as yet and long-stay demand is considered to be limited.

\section{Brentford}

Brentford is located along the 'Golden Mile' of the A4, where the national and international headquarters of companies including GlaxoSmithKline, Carrillion, Gillette and Data-General are located. Chiswick Park, in Gunnersbury, is, after Canary Wharf, the largest commercial development in London. A second phase of the Bedfont Lakes Technopark development is under way and this will promote further expansion in the already growing field of high-technology. Other business parks in the wider area include Park Royal and Stockley Park.

Brentford is a rapidly developing business hub that accommodates the headquarters of several large multinational companies. Therefore, Brentford has the demand for extended stay products and it already offers internationally branded and unbranded serviced apartments. Two serviced apartment properties are owned and managed by Clarendon Serviced Apartments in the surrounding area: the Clarendon House and Gardens, and Manning Place. The town centre offers a limited range and choice of shops, services, and leisure and entertainment facilities such as restaurants and evening entertainment.

In general, Brentford is considered to be an area with significant mediumstay and long-stay demand that is generated predominantly by international corporations involved with training or special long-term projects.

\section{Coventry}

Coventry's loss of its strong economic position and widespread importance, with the demise of its bicycle and car industries, has 
translated into a transitory period of economic downturn, characterised by high unemployment and a gradual deterioration of those parts of the city that were most severely hit. The city council has, however, successfully set up and implemented the Coventry Development Plan, which is aimed at regenerating the city as an entity, thus encouraging company investment and inbound migration. The Ricoh Arena is just one of the many examples of new development in the city that is aimed at making Coventry more attractive. Coventry is likely to position itself at the top end of the list of similarly sized cities in the UK in terms of its propensity to attract investment, its attractiveness enhanced by the city's ideal location in the heart of England.

Medium-stay business demand in the market area is derived mainly from local business and the Ricoh Arena. At peak times for exhibitions, conferences and trade fairs, the National Exhibition Centre in Birmingham has a positive impact on the occupancy of Coventry's hotels.

Leisure demand in the market area is derived mainly from travellers visiting friends and relatives. Most of the leisure demand, however, is short stay, as Coventry has only two main tourist attractions: the remains of the historic cathedral and the new cathedral.

Extended stay business demand in the market area is relatively low, as the surrounding business consists mainly of local and national companies that do not require extended stay accommodation. We conclude that Coventry lacks a significant number of long-stay demand generators, and we forecast no significant growth in extended stay in the near future.

\section{Farnborough}

Farnborough benefits from strong levels of corporate room demand generated from local businesses and this is supported by a moderate number of leisure travellers. The development of the town centre and Farnborough's IQ Business Park is, however, expected to have some positive impact on leisure visitation.

Over the next few years, major redevelopment work will take place and this will transform parts of Farnborough. With continued and increased growth in the business sectors, these developments are likely to become a catalyst for sustained demand growth in the area.

Medium-stay business demand in the market area is derived mainly from the technology-based businesses and research institutions in the area. These industries give rise to project-oriented work of a couple of weeks and require staff to attend specialised training courses.

Farnborough, for instance, has a flight simulator training centre near the airport. Future extended stay business demand is tied primarily to the business and economic health of the UK. In Farnborough, extended stay demand is driven most notably by FlightSafety, which is responsible for the training of pilots at its flight simulator centre at Farnborough airport. Trainees typically require several weeks' accommodation during their visit.

We note that it is often common practice to locate an extended stay hotel near to a strong driver of corporate demand, such as an extensive business park. We, however, note the risk of a property's operating more like a conventional business hotel and less like an extended stay product. 
Table 5: Indicative construction cost per room in the UK (€/key)

\begin{tabular}{llc}
\hline & \multicolumn{2}{l}{ Range } \\
\cline { 2 - 3 } & Low & High \\
\hline Upscale & 170,000 & 472,000 \\
Mid-market & 82,000 & 161,000 \\
Budget & 52,000 & 78,000 \\
\hline
\end{tabular}

Note: Excludes land cost and finance

Source: HVS Research and Gleeds

\section{London}

Many internationally branded extended stay products are introduced in European gateway cities first, and therefore it is not surprising that London is home to numerous branded and unbranded serviced apartment operators. The extended stay market in London features mid-market brands (such as Citadines) and upscale and luxury products (such as Marriott Executive Apartments, and Fraser). Business districts such as the City and Canary Wharf have seen an increase in extended stay products in recent years, particularly in the mid-range and upscale category for nonexecutive guests, as City workers prefer to stay close to the workplace. More expensive residential areas such as Mayfair, and Kensington and Chelsea are dominated by a supply of luxury products.

As an international business hub, London is a market that is particularly resilient to recession. In addition, the city has a strong leisure and cultural profile that makes it attractive all year round. Demand for extended stay products (and hotels, to some extent) is generated mostly by companies needing temporary accommodation for their employees or visitors, on account of relocation or special projects. Some of the major international corporations in the surrounding area include UBS, ABN AMRO, the Royal Bank of Scotland, SwissRe, the Bank of England, BT Group plc and Lloyds TSB Group plc. A large number of companies having their headquarters in London gives rise to training at the base and headquarters secondments, both of which are classic extended stay target markets. London is popular too with wealthy middle eastern and Russian families who like to have a spacious 'base' in an international shopping capital.

Owing to London's thriving arts and cultural scene, performing artists and the like also provide demand for extended stay hotels.

The extended stay hotel business is linked somewhat to the general real estate situation in a destination. In London, renting a suitable value-formoney apartment in a city centre location can be difficult, so this might not be a particularly appealing option for visitors.

Although London will see an impressive array of new extended stay products coming on stream over the next few years, we estimate that demand will outstrip supply in the medium to long term.

\section{Newcastle upon Tyne}

The extended stay market in Newcastle is not yet well established; however, two smaller operators are present. The main employers and companies in the area are Northern Rock, Sage Group, Procter \& 
Gamble, Fenwick, Akzo Nobel International Coatings and AA Insurance Services. At present, these companies generate demand for transient accommodation from Monday to Thursday with employees on training or attending meetings and conferences. The city has two universities: Newcastle University and the newer Northumbria University. Our analysis revealed that the universities induce demand for extended stay through guest lecturers, conference participants, and friends and relatives visiting students.

Furthermore, Newcastle Hospitals Trust One is ranked second in the country for patients' confidence in doctors. Newcastle has three large teaching hospitals: the Royal Victoria Infirmary, whose organ donor system has been featured on television; Newcastle General Hospital; and the Freeman Hospital, which is Britain's leading transplant centre. Our research revealed that demand for extended stay generated by the hospitals comes through friends and relatives visiting in-patients, or doctors on training.

Individual leisure and group leisure demand in Newcastle have been very strong at the weekend, mainly because the city is very popular for its retail possibilities and its vibrant nightlife, which caters for hen nights and stag nights.

In general, we envisage demand for extended stay following similar patterns to transient demand for hotel accommodation in the Newcastle area. This means mainly corporate demand filling the rooms during the week and leisure demand occupying the rooms at weekends. We project that the introduction of more extended stay products and the establishment of the extended stay market in the Newcastle area would, however, change corporate traveller patterns for those guests needing to be in Newcastle for several weeks or months at time, encouraging them not to leave for the weekend but to stay for the whole week (Monday to Sunday) for several weeks.

\section{Milton Keynes}

As a commercial centre, Milton Keynes has been particularly successful in attracting companies looking to relocate back-office staff from London, as well as in attracting international companies aiming to establish or grow a UK base. DaimlerChrysler, Argos, BP, Suzuki, Coca-Cola and VW Audi are among the blue-chip companies to have set up offices or manufacturing plants in Milton Keynes. The local government and local education and scientific organisations recently signed a memorandum of understanding to set up resources to further attract and support start-up companies and technology-led businesses in an effort to boost Milton Keynes' profile as a centre of technology, entrepreneurship and innovation.

Besides concertgoers and those attending major events, we note that the majority of visitors coming to Milton Keynes are day visitors and hey do not generate demand for hotel accommodation. As a result, weekend demand in the market area is relatively limited. Medium-stay business demand in the market area is derived mainly from local businesses. 
Table 6: Comparison of pro forma operating performance

\begin{tabular}{lll}
\hline Factor & Full service & Extended stay \\
\hline Number of units & 100 & 100 \\
Occupancy* & $70 \%$ & $75 \%$ \\
Average rate $(€)^{*}$ & 100 & 100 \\
Room nights sold & 25,550 & 27,375 \\
DOF & 1.3 & 1.3 \\
Length of stay & Two days & Ten days \\
Rooms revenue $(€)$ & $2,555,000$ & $2,737,500$ \\
F\&B revenue & Higher & Lower \\
Total revenue & Higher & Lower \\
Operating expenses & $45-65 \%$ & $25-45 \%$ \\
GOP & $25-45 \%$ & $45-65 \%$ \\
\end{tabular}

*The difference between the full service and the extended stay product is highly dependent on market conditions Source: HVS estimates

Demand throughout the medium-stay segment shows fairly even seasonality patterns over the course of the year, owing to a reduced level of guest fluctuation following individual necessities. Therefore, we expect this segment to show no peaks or troughs in its demand patterns.

In common with other secondary UK cities, Milton Keynes has an extended stay market that is not yet well-established. The town offers only a group of unbranded serviced apartments with a total of 65 units.

We conclude that, at the moment, extended stay products would fill in a manner similar to that of hotels in the area: commercial demand during the week and limited leisure demand at the weekend.

\section{Other destinations}

Other possible extended stay locations in the UK include the following:

- Liverpool;

- Manchester;

- Birmingham;

- Edinburgh;

- Glasgow.

\section{DEVELOPING AND OPERATING AN EXTENDED STAY HOTEL}

Since extended stay hotels are a relatively new concept in the UK, construction costs play an essential role when a hotel project's return on investment is to be calculated. Our industry experience suggests that construction costs in the UK are relatively high compared to those in other European countries. This is true for the building construction costs, furniture, fixtures and equipment (FF\&E) costs and, most importantly, land costs. Although these can vary between city centre and provincial locations, we note that land costs in prime central locations in cities such as London, Edinburgh, Glasgow and Manchester can be high. We note too that the cost of business park land in more rural areas can account for a large proportion of the total development cost.

Extended stay products have the advantage of lower construction costs, compared to a full service hotel of similar quality, thanks to cost 
efficiencies, smaller public areas and fewer food and beverage facilities. Construction costs and land costs vary widely throughout Europe.

We note that extended stay hotels achieve, on average, a 10-15 per cent reduction in construction costs (these costs comprise building costs, FF\&E and professional fees) per room. Indicative construction cost estimates for the UK are shown in Table 5.

These savings are made predominantly through lower FF\&E costs. Although one has to consider extra costs for kitchen and living space in an extended stay room, such a hotel has limited public areas (restaurant, professional kitchens, meetings space, and so forth), and this lowers the total FF\&E cost per room.

When considering development risk, one can also argue that, location permitting, an extended stay hotel can be easily converted into residential apartments that can be sold individually.

The operating characteristics of the extended stay product deviate from those of a standard hotel. We therefore discuss the main drivers for income and expense below.

\section{Pricing (average rate)}

In general, daily rack rates at an extended stay product might be slightly higher compared to hotels (depending on the market), since the former offers a larger living space and greater comfort. In addition, extended stay products apply a tiered discount structure based on the length of stay. A typical full service hotel segments demand into corporate, leisure and group customers, whereas the rate structure for extended stay products is usually based on length of stay. This would typically start at rack rate for stays of up to one week. For stays of between seven and 14 days the discount is usually around 10 per cent. Further discounts (of about 20 per cent) will be granted for stays of more than two weeks. In addition to discounts depending on the length of stay, corporate discounts typically apply and these might be as high as $15-20$ per cent on the aforementioned discounts.

If the extended stay hotel market is not well represented in the area, or if it is newly established, then the availability and cost of renting an apartment in the traditional real estate market needs to be reviewed too.

\section{Occupancy}

In general, occupancy is greatly influenced by the same supply and demand factors that affect similar hotels and modestly priced apartments. Usually, stabilised extended stay hotels run at occupancies similar to or even higher than their competitors in the hotel sector because extended stay hotels are less affected by weekday-weekend seasonality, as guests have a longer average length of stay. Extended stay hotels benefit from lower guest turnover and therefore the cost of selling a particular room every night and the risk of failing to sell the room are significantly reduced. Careful management of the room inventory is required to obtain the highest occupancy possible, along with the highest percentage of extended stay customers possible, instead of trying to sell out every night. Maintenance of high occupancy is therefore linked to staying true 
to the extended stay nature of the property. Some properties demand a minimum length of stay of three to seven days in an attempt to attract long-stay clientele.

\section{Revenues}

If we assume that average rate and occupancy are similar to or higher than they are in a conventional hotel, then rooms revenues should be higher as well. The rooms revenue category is, of course, the most important one for this type of hotel, which lacks other revenue sources such as restaurants, meeting and banqueting space, and retail outlets.

Other income might be generated through telephone, vending machine (or sometimes food stores and bars) and guest laundry revenues. Other income is important, but minimal when compared to the amount of rooms revenue collected. Total revenue is therefore driven by rooms revenue predominantly. In general, we assume that total revenue to be slightly higher in a full service hotel compared to an extended stay product.

\section{Operating expenses}

The main cost savings in an extended stay product compared to a hotel are lower expenses in the food and beverage service, owing to selfcatering, no or a very limited number of food and beverage outlets, and streamlined staffing in all departments. Fewer front-desk personnel (as the extended stay product sees fewer check-ins and check-outs) and limited housekeeping service (or dependent on extra charges) are just a few other reasons why cost savings result. A typical 100-key extended stay product would have about 15-20 employees compared to at least double that number in a full service midscale hotel.

\section{Profit margin}

Significantly lower operating expenses result in higher profit margins for the extended stay product. Table 6 shows a pro forma comparison between a full service midscale hotel and an extended stay product. We note that these pro forma operating performances are of an indicative nature only and assume that the property is in a European gateway city.

\section{OUTLOOK}

The future expansion plans of several operators have been announced. During our research we approached the main operators and asked them for their expansion plans in Europe in the short to medium term.

Marriott International is currently revising its extended stay strategy for the EMEA region by looking at different options. No decisions have been made to date.

When it comes to the EMEA region, Starwood, with its recently announced Element brand, is witnessing swift pick-up in the middle east. In the medium-term European capitals too are on the list for possible Element developments.

Hyatt has no plans at the moment to introduce its US extended stay brand in Europe. 
Adina, currently with three properties in the European market, has already announced another five extended stay hotels within the next two years in Germany. And there is more to come, as Germany is one of Adina's two key markets. Adina is looking intensively for opportunities, probably in cities such as Stuttgart, Cologne, Düsseldorf and Munich. Adina also considers secondary cities with strong corporate demand such as Dresden and Leipzig. Besides Germany, the other key market is the UK; Adina will start looking there by the end of 2008. Its strategy for the medium term is to really focus on these two markets and become one of the market leaders in extended stay hotels there.

IHG is currently pursuing a three-pronged strategy for Staybridge Suites: the UK, Russia and the middle east. Staybridge Suites is envisaging properties in continental Europe only in the medium term, potentially starting with Germany. The current focus, however, remains the UK. In addition to its first property in Liverpool, IHG has signed sites in Newcastle; two in each of London and Birmingham; and in Glasgow and Cardiff, with 30 additional UK locations under consideration. A number of sites will be co-branded with other IHG properties, but will remain stand-alone long-stay hotels. The Russian sites are close to completion and include destinations such as Moscow, $\mathrm{St}$ Petersburg and other major provincial cities.

Pierre \& Vacances' and Accor's joint efforts under the Adagio brand have focused on France so far, but the growth strategy foresees expansion into Germany, the UK and eastern Europe. Discussions about projects in London, Manchester and Birmingham are at an advanced stage. In Germany, the centres of attention are Berlin, Munich and Hamburg, whereas the focus in eastern Europe is on Budapest and Bucharest. Russia is also of interest to the joint venture, which wants to reach the goal of 50 residences by 2012.

The Ascott Group currently operates only one Ascott-branded property in Europe (in London), but it is considering further luxury properties in Paris and London. After a few years of slowed development activity, Ascott is planning to refresh the Citadines product in order to stay ahead of the game, given the new extended stay brands in the three-star and four-star segments. Future projects include locations such as Munich, Edinburgh, Aktau (Kazakhstan) and Tbilisi (Georgia).

\section{CONCLUSION}

In theory, the extended stay product should not compete with regular hotels, and should remain a complementary product. This theory, however, may be challenged in an oversupplied or secondary market, where long-stay demand is not sufficient to fill the hotel. It should be noted that the benefit of the extended stay product (a higher profit margin) can be drawn only by filling the hotel with long-stay guests rather than with short-stay customers; to do otherwise would mean that operating expenses would increase and profit margins would shrink. Despite the higher room rate obtained for the short-term guest, this customer base is neither appropriate for nor sought by the extended stay product. If management seeks to increase its short-stay capture and therefore focuses 
on increasing its average rate for the property, occupancy will inevitably be sacrificed. It is more effective for the extended stay product to sell one room to a single customer for a four-week stay than to try to sell the room to 28 different customers for a stay of one night each.

As the extended stay market in Europe has not yet been established, we foresee the following challenges for European extended stay hotels.

- Establishing themselves in locations with a high proportion of extended-stay clientele;

- Resisting the temptation to market and run the serviced apartment operation as a conventional hotel.

Finding an appropriate mix of units (studios, one-bedroom, two-bedroom and three-bedroom apartments) that has enough earning capacity to outweigh construction costs and increase the developer's return on investment. 